\title{
PENGARUH WAKTU TUNGGU, HARGA DAN KUALITAS PELAYANAN TERHADAP KEPUASAN KONSUMEN PADA MASKAPAI PENERBANGAN AIR ASIA DI TERMINAL 2D BANDARA SOEKARNO HATTA
}

\author{
R. Adam Kesuma Phaksi \\ Program Studi Magister Manajemen Universitas Tarumanagara \\ hai.rendyadams@gmail.com
}

Masuk : 07-12-2020, revisi : 17-12-2020, diterima untuk diterbitkan : 18-12-2020

\begin{abstract}
The purpose of this study is to determine the effect of waiting time, price, and service quality on customer satisfaction on Air Asia airlines at terminal 2D Soekarno Hatta Airport. Respondents in this study are people who have used the services of the Air Asia airline at terminal 2D Soekarno Hatta airport. Respondents in this study were 100 people, and the sampling technique used was purposive sampling. The data analysis technique uses Multiple Linear Regression using application SPSS version 25 software. The results indicate that waiting time, prices and service quality has an effect on customer satisfaction on Air Asia airlines at terminal 2D Soekarno Hatta airport.
\end{abstract}

Keywords: Waiting Time, Price, Service Quality, Consumer Satisfaction

\begin{abstract}
Abstrak: Penelitian ini bertujuan untuk mengetahui (1) pengaruh waktu tunggu secara parsial terhadap kepuasan konsumen pada maskapai penerbangan Air Asia di terminal 2D Bandara Soekarno Hatta, (2) pengaruh harga secara parsial terhadap kepuasan konsumen pada maskapai penerbangan Air Asia di terminal 2D Bandara Soekarno Hatta, (3) pengaruh kualitas pelayanan secara parsial terhadap kepuasan konsumen pada maskapai penerbangan Air Asia di terminal 2D Bandara Soekarno Hatta. Penelitian ini menggunakan 100 responden yang telah menggunakan jasa penerbangan maskapai Air Asia di terminal 2D bandara Soekarno Hatta. Penelitian ini menggunakan teknik purposive sampling dalam pengambilan sample. Penelitian ini menggunakan Regresi Linier Berganda dalam analisis data dan menggunakan aplikasi SPSS versi 25. Hasil dari penelitian ini menunjukkan bahwa (1) Adanya pengaruh secara parsial waktu tunggu terhadap kepuasan konsumen pada maskapai penerbangan Air Asia di terminal 2D bandara Soekarno Hatta, (2) Adanya pengaruh secara parsial harga terhadap kepuasan konsumen pada maskapai penerbangan Air Asia di terminal 2D bandara Soekarno Hatta, (3) Adanya pengaruh secara parsial kualitas pelayanan terhadap kepuasan konsumen pada maskapai penerbangan Air Asia di terminal 2D bandara Soekarno Hatta.
\end{abstract}

Kata Kunci: Waktu Tunggu, Harga, Kualitas Pelayanan, Kepuasan Konsumen

\section{PENDAHULUAN}

Daya tarik (attractiveness) dalam industri penerbangan saat ini sangat kuat dan menjanjikan, dilihat dari banyaknya perusahaan maskapai penerbangan yang semakin menjangkau masyarakat. Tidak terkecuali dengan maskapai Air Asia, yaitu maskapai penerbangan yang menerapkan penerbangan bertarif murah (low-cost carrier) dengan tetap memberikan kualitas pelayanan yang sebaik mungkin.

Penerbangan bertarif murah ini juga banyak diterapkan oleh maskapai penerbangan lainnya, karena tingginya minat dan kebutuhan masyarakat menggunakan jasa penerbangan. Harapannya mereka ingin menghemat waktu perjalanan untuk sampai di tujuan, jika dibandingkan dengan jasa transportasi lainnya.

Selain waktu tempuh, konsumen juga melihat dari sisi harga. Harga yang ditawarkan oleh perusahaan maskapai penerbangan saat ini sangat kompetitif dan dapat memberikan pengaruh baik terhadap pertumbuhan harga pasar. Karena harga adalah hal yang penting dalam sebuah 
bisnis. Menurut Gitosudarmo (2000, p. 32), "Harga adalah sejumlah nilai yang ditukarkan konsumen dengan manfaat dari memiliki atau menggunakan produk atau jasa yang nilainya ditetapkan oleh pembeli atau penjualan melalui tawar menawar atau ditetapkan oleh penjual untuk suatu harga yang sama terhadap semua pembeli”. Oleh sebab itu, alangkah baiknya jika perusahaan lebih teliti dalam menetapkan suatu harga yang memiliki dampak pada besarnya nilai laba perusahaan.

Sebagai perusahaan yang bergerak di bidang jasa, Air Asia menyadari bahwa harga, waktu tunggu dan kualitas pelayanan menjadi hal yang penting dalam meningkatkan kepuasan konsumen. Kualitas pelayanan yang baik ataupun buruk tentu akan membangun kesan tersendiri bagi konsumen. Kualitas pelayanan yang terbaik harus senantiasa menjadi prioritas utama bagi perusahaan maskapai penerbangan demi mempertahankan kehadirannya di dunia penerbangan.

\section{TINJAUAN PUSTAKA Waktu Tunggu}

Waktu tunggu ialah waktu yang digunakan consumer guna mendapatkan pelayanan maupun sarana dari service tersebut. Lamanya waktu tunggu yang dihadapi consumer mencerminkan bagaimana sebuah maskapai mengelola komponen pelayanan supaya harapan consumer terpenuhi dengan segala situasi. Waktu tunggu akan menjadi masalah bagi perusahaan jasa ketika kapasitas yang ada tidak mencukupi permintaan consumer, sehingga mengakibatkan lamanya waktu tunggu atau panjangnya antrian. Hal ini disebabkan karena adanya keragaman permintaan dan pelayanan yang diberikan. Lovelock dan Gummesson (2004) juga berpendapat pentingnya peran waktu tunggu suatu perusahaan jasa dan menyarankan untuk memberikan lebih banyak perhatian dalam memperbaiki dan mengerti nilai waktu tunggu bagi consumer.

\section{Harga}

Dalam dunia bisnis harga memiliki berbagai sebutan, sebagai contoh dalam dunia perdagangan produk disebut harga (price), dalam dunia perbankan disebut bunga (bank interest), atau dalam dunia bisnis jasa akuntansi, konsultan disebut fee, dalam dunia telepon disebut tarif, sedangkan dalam dunia asuransi disebut premi. Menurut Kotler dan Keller (2009, p. 67), "harga adalah satu- satunya elemen yang menghasilkan pendapatan, elemen lainnya menghasilkan biaya”. Menurut Swastha (2003, p. 114), berikut peranan harga bagi suatu perusahaan:

1. Harga merupakan suatu factor penentu jumlah permintaan product di pasar.

2. Harga menentukan nilai hasil penjualan dan keuntungan.

3. Harga dapat berpengaruh pada segmen pasar yang ditembus oleh perusahaan.

4. Harga dan strategi berpengaruh pada keberhasilan distribusi product.

5. Harga mempunyai pengaruh terhadap implementasi program promosi penjualan.

Menurut Mulyadi (2001, p. 78), "pada prinsipnya harga jual harus dapat menutupi biaya penuh ditambah dengan profit yang wajar. Harga jual sama dengan biaya produksi ditambah mark-up".

\section{Kualitas Pelayanan}

Menurut Tjiptono (2007, p. 59), pengertian "kualitas pelayanan adalah tingkat keunggulan yang diharapkan dan pengendalian atas keunggulan tersebut untuk memenuhi keinginan pelanggan". Dengan begitu, kualitas pelayanan dapat didefinisikan "Seberapa jauh perbedaan antara kenyataan dan harapan pelanggan atas layanan yang mereka terima atau peroleh". Ada dua factor utama yang memengaruhi kualitas jasa, yaitu expected service (jasa yang diharapkan) dan perceived service (jasa yang disarankan). Penting bagi suatu perusahaan yang bergerak di bidang jasa untuk memperhatikan kualitas pelayanan demi memenuhi kepuasan konsumennya. 


\section{Kepuasan Konsumen}

Kepuasan konsumen merupakan bagian terpenting dalam perusahaan. Maka dari itu kita sering melihat atau mendengar slogan "pelanggan adalah raja". Menurut Band dalam Nasution (2005), menyebutkan bahwa kepuasan bisa tercapai jika memenuhi kualitas, melebihi harapan, keinginan dan kebutuhan consumer. Sebaliknya, jika kualitas tidak terpenuhi dan tidak melebihi harapan, keinginan dan kebutuhan consumer maka kepuasan tidak tercapai. Consumer yang tidak puas terhadap suatu barang atau jasa yang dikonsumsinya akan mencari perusahaan lain yang mampu memenuhi kebutuhannya.

\section{Kerangka Pemikiran}

\section{Gambar 1}

Kerangka Pemikiran

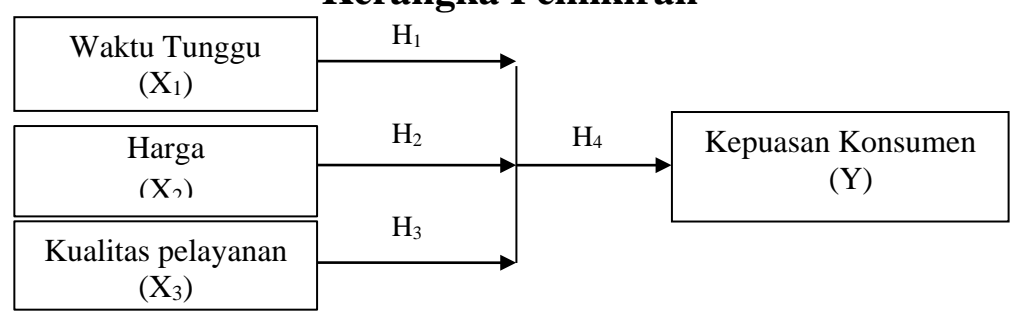

\section{Hipotesis}

H1 : Waktu tunggu (X1) berpengaruh secara partial dan significant terhadap Kepuasan Konsumen (Y)

H2 : Harga (X2) berpengaruh secara partial dan significant terhadap Kepuasan Konsumen (Y)

H3 : Kualitas Layanan (X3) secara partial berpengaruh dan significant terhadap Kepuasan Konsumen (Y)

H4 : Waktu Tunggu (X1), Harga (X2) dan Kualitas Pelayanan (X3) berpengaruh secara simultan dan significant terhadap Kepuasan Konsumen (Y)

\section{METODOLOGI PENELITIAN}

\section{Sumber dan Jenis Data}

Jenis data yang digunakan dalam research ini berupa data primer. Data primer dalam research ini diperoleh dari kuesioner yang diisi secara langsung oleh responden melalui Google Form dan pendalaman yang dilakukan oleh peneliti. Responden dalam research ini adalah konsumen/penumpang yang pernah menggunakan jasa maskapai penerbangan Air Asia di Terminal 2D Bandara Soekarno Hatta. Penelitian ini menggunakan sample sebanyak 100 responden. Menurut Supranto (2001:14), ukuran sample yang tepat memiliki responden sebanyak 30, dimana semakin banyak sample maka akan memberi dampak hasil yang semakin akurat. Penelitian ini menggunakan teknik Purposive Sampling. Menurut Sugiyono (2005), purposive sampling adalah teknik penentuan sampling dengan pertimbangan tertentu.

\section{HASIL \& PEMBAHASAN}

\section{Analisis Regresi Linier Berganda dan Uji t}

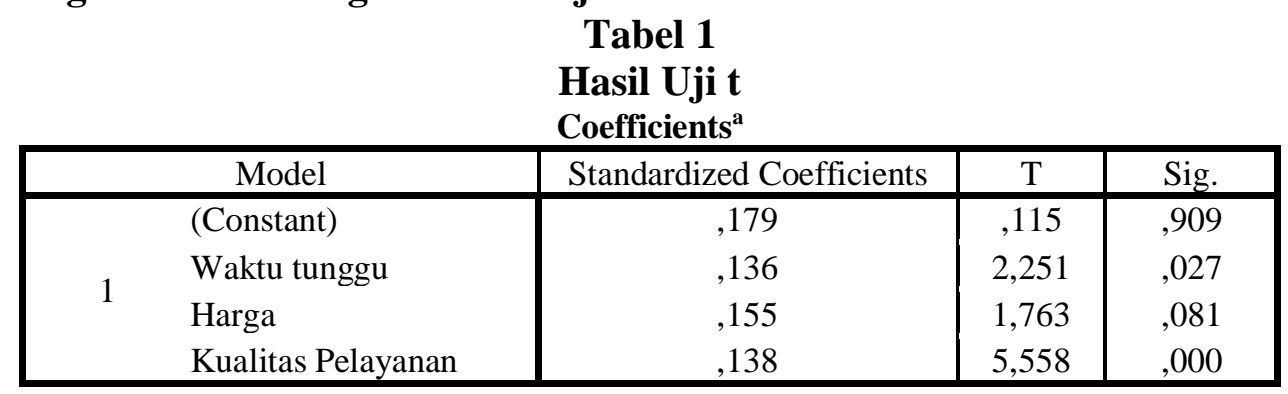

a. Dependent Variable: Kepuasan Konsumen

Sumber: primary data diolah menggunakan SPSS versi 25 
Dari tabel di atas didapat $\mathrm{a}=\mathbf{0 . 1 7 9}, \mathrm{b}^{1}=\mathbf{0 . 1 3 6}, \mathrm{b}^{2}=\mathbf{0 . 1 5 5}$ dan $\mathrm{b}^{3}=\mathbf{0 . 1 3 8}$ sehingga dapat diketahui persamaan regresinya adalah:

$$
\mathrm{Y}=0.179+0.136 \mathrm{X} 1+0.155 \mathrm{X} 2+0.138 \mathrm{X3}+\varepsilon
$$

Terlihat bahwa nilai constant (a) yaitu senilai 0.179. Adanya parameter positif yang ditunjukkan variabel Waktu Tunggu $\left(\mathrm{b}^{1}\right)$ dengan nilai 0.136, ini menunjukkan customer satisfaction akan meningkat jika waktu tunggu semakin baik. Adanya parameter positif yang ditunjukkan variabel harga $\left(\mathrm{b}^{2}\right)$ dengan nilai $\mathbf{0 . 1 5 5}$, ini menunjukkan customer satisfaction akan meningkat jika harga semakin baik. Adanya parameter positif yang ditunjukkan variabel kualitas pelayanan $\left(\mathrm{b}^{3}\right)$ dengan nilai $\mathbf{0 . 1 3 8}$, ini menunjukkan customer satisfaction akan meningkat jika kualitas pelayanan semakin baik. Dapat diketahui pula hasil $\mathrm{t}$ hitung:

a. Secara parsial waktu tunggu (waiting time) berpengaruh terhadap customer satisfaction sebanyak 2.251 dengan sig. $0,027<\alpha=0,05$. Ini berarti hipothesis yang menjelaskan waktu tunggu memiliki pengaruh terhadap customer satisfaction diterima.

b. Secara parsial kualitas pelayanan (service quality) berpengaruh terhadap customer satisfaction sebesar 5.558 dengan sig. $0,000<\alpha=0,05$. Ini berarti hipothesis yang menjelaskan kualitas pelayanan memiliki pengaruh terhadap customer satisfaction diterima.

c. Secara parsial harga (price) berpengaruh terhadap customer satisfaction sebanyak 1.763 dengan sig. $0,041<\alpha=0,05$. Ini berarti hipothesis yang menjelaskan harga memiliki pengaruh terhadap customer satisfaction diterima.

Harga adalah faktor yang paling berpengaruh terhadap customer satisfaction maskapai penerbangan Air Asia di Terminal 2D Bandara Soekarno Hatta, karena variabel harga memiliki nilai regresi terbesar.

\section{Analisis Koefisien Determinasi}

\section{Tabel 2}

Hasil Uji Koefisien Determinasi

Model Summary ${ }^{\mathrm{b}}$

\begin{tabular}{|c|c|c|c|c|}
\hline Model & $\mathrm{R}$ & $\mathrm{R}$ Square & Adjusted R Square & Std. Error of the Estimate \\
\hline 1 & $.766^{\mathrm{a}}$ & .586 & .573 & 1.235 \\
\hline
\end{tabular}

a. Predictors: (Constant), Waktu Tunggu, Harga, Kualitas Pelayanan

b. Dependent Variable: Kepuasan Konsumen

Sumber: primary data diolah menggunakan SPSS versi 25

Variabel bebas yang diteliti berhubungan kuat dengan variabel terikat karena koefisien korelasinya $(\mathrm{R}=0,766)$. Koefisien determinasi ( $R$ Square) 0,573. Ini menunjukkan bahwa $57,3 \%$ variabel bebas berengaruh terhadap variabel terikat, dan $42,7 \%$ dipengaruhi oleh variabel independen yang tidak terdapat dalam penelitian.

Uji F

Uji Hipotesis menggunakan uji $\mathrm{F}$ hitung dengan ketentuan jika $\mathrm{F}$ hitung lebih besar dari (>) $\mathrm{F}$ tabel, maka $\mathrm{Ha}$ diterima dan Ho ditolak, sebaliknya jika $\mathrm{F}$ hitung kurang dari $(<) \mathrm{F}$ tabel maka $\mathrm{Ha}_{\mathrm{a}}$ ditolak dan $\mathrm{Ho}_{\mathrm{o}}$ diterima.

Tabel 3

Hasil Uji F

ANOVA

\begin{tabular}{|ll|c|c|c|c|c|}
\hline \multicolumn{1}{|c|}{ Model } & Sum of Squares & Df & Mean Square & F & Sig. \\
\hline 1 & Regression & 207.485 & 3 & 69.162 & 45.316 & $.000 \mathrm{~B}$ \\
Residual & 146.515 & 96 & 1.526 & & \\
Total & 354.000 & 99 & & & \\
\hline
\end{tabular}

a. Predictors: (Constant), Waktu Tunggu, Harga dan Kualitas Pelayanan

b. Dependent Variable: Kepuasan Konsumen

Sumber: primary data yang diolah menggunakan SPSS versi 25 
Hasil Uji F menunjukkan adanya pengaruh secara simultan antara harga, kualitas pelayanan dan waktu tunggu terhadap kepuasan konsumen senilai 45.316 dengan sig. $0,000<$ $\alpha=0,05$. Hasil ini menjelaskan bahwa hypothesis yang menyatakan harga, kualitas pelayanan dan waktu tunggu berpengaruh terhadap kepuasan konsumen diterima.

\section{Kesimpulan}

Kesimpulan dari penelitian ini adalah:

1. Hasil perhitungan statistik menunjukkan nilai F hitung (45.316) > F tabel (0.00) dan nilai signifikannya $0,000^{\mathrm{a}}<0,05$. Berarti secara simultan hasil uji statistik dinyatakan berpengaruh positif dan signifikan.

2. Uji statistik secara parsial menyatakan variabel waktu tunggu (X1) berpengaruh positif dan signifikan terhadap kepuasan konsumen (Y). Hal ini dibuktikan dengan t hitung senilai 2.251 tingkat signifikansinya $0,027<0,05$ berarti hipotesis dalam penelitian ini Ha diterima dan Ho ditolak.

3. Uji statistik secara parsial menyatakan variabel kualitas pelayanan (X3) berpengaruh positif dan signifikan terhadap kepuasan konsumen (Y). Hal ini dibuktikan dengan $\mathrm{t}$ hitung senilai 5.558 tingkat signifikansinya $0,000<0,05$ berarti hipotesis dalam penelitian ini Ha diterima dan Ho ditolak.

4. Uji statistik secara parsial menyatakan variabel harga (X2) berpengaruh positif dan signifikan terhadap kepuasan konsumen (Y). Hal ini dibuktikan dengan t hitung senilai 1.763 tingkat signifikansinya $0,041<0,05$ berarti hipotesis dalam penelitian ini $\mathrm{Ha}$ diterima dan Ho ditolak.

\section{Implikasi Manajerial}

Berkaitan dengan hasil penelitian ini, penulis menyampaikan beberapa implikasi manajerial yang bisa diterapkan oleh maskapai Air Asia.

1. Penerbangan bertarif rendah (Low-Cost Carrier) sudah diterapkan oleh beberapa maskapai penerbangan lainnya, penting bagi maskapai Air Asia untuk secara berkala memperhatikan waktu tunggu, harga dan kualitas pelayanan agar tetap mampu mempertahankan keunggulan yang dimiliki dan membenahi kekurangan yang terjadi.

2. Menjaga harga tiket pesawat dan pelayanan penunjang lainnya demi menjaga kepuasan konsumen. Karena dalam penelitian ini menunjukkan bahwa harga memiliki pengaruh yang paling kuat terhadap kepuasan konsumen

3. Maskapai penerbangan Air Asia juga perlu memperhatikan pentingnya variabel lain diluar penelitian ini guna menjaga kepuasan konsumen yang telah diraih saat ini.

\section{DAFTAR PUSTAKA}

Gitosudarmo, I. (2000). Manajemen pemasaran (1st ed.). BPFE-Yogyakarta.

Kotler, P., \& Keller, K. L. (2009). Manajemen pemasaran (13th ed.). Erlangga.

Lovelock, C., \& Gummesson, E. (2004). Whither services marketing?: In search of a new paradigm and fresh perspectives. Journal of Service Research, 7(1), 20-41.

https://doi.org/10.1177/1094670504266131

Mulyadi. (2001). Sistem akuntansi (3rd ed.). Salemba Empat.

Nasution. (2005). Total quality nanagement. PT Gramedia Pustaka Utama.

Sugiyono. (2005). Metode penelitian bisnis (2nd ed.). Alfabeta CV.

Swastha, B. (2003). Saluran pemasaran. BPFE-Yogyakarta.

Tjiptono, F. (2007). Strategi pemasaran (2nd ed.). Andi. 